\title{
Carcinogenic Cyclic Nitrosamine
}

National Cancer Institute

\section{Source}

National Cancer Institute. Carcinogenic Cyclic Nitrosamine. NCI Thesaurus. Code C45402.

A ring compound that increases the risk of human cancer and is a $\mathrm{N}$-nitroso derivative of secondary amines (R2N-NO), formed by combining nitrates with amines. ( $\mathrm{NCl05})$ 